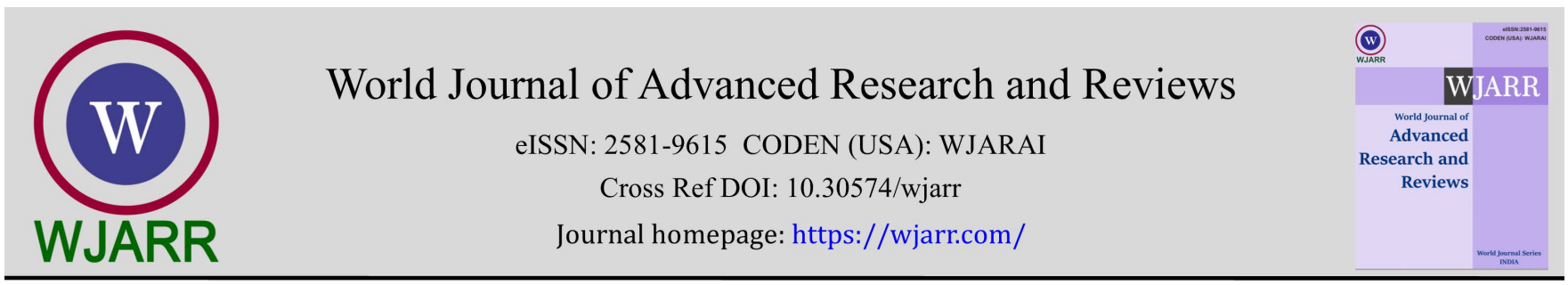

(REVIEW ARTICLE)

\title{
Attenuation of the onset and progression of age-related vision impairments by reducing oxidative stress and inflammation by micronutrients
}

\author{
Kedar N Prasad * \\ Engage Global, inc. 245 El Faisan Drive, San Rafael, CA 94903.
}

World Journal of Advanced Research and Reviews, 2021, 12(03), 045-056

Publication history: Received on 02 September 2021; revised on 16 October 2021; accepted on 18 October 2021

Article DOI: https://doi.org/10.30574/wjarr.2021.12.3.0425

\begin{abstract}
The major eye diseases refractive error, cataract, age-related macular degeneration (ARMD), glaucoma, and diabetic retinopathy can lead to blindness without an early intervention. The treatments include eye glasses for refractive error, surgery for cataract, and medications for glaucoma and ARMD. These therapies do not address oxidative stress and inflammation that contribute to these eye diseases. Therefore, supplementation with antioxidants could be useful. However, administration with single or multiple dietary antioxidants with or without carotenoids (zeaxanthin and lutein), and omega-3-fatty acids, produced no benefits or only modest benefits in certain eye diseases. The problems associated with such antioxidant's approaches were identified, and potential causes for not producing optimal benefits were presented. The major objectives are to show that enhanced oxidative stress and inflammation contribute to the age-related major eye diseases. This review presents rationales for using a comprehensive mixture of micronutrients containing dietary and endogenous antioxidants, vitamin D3, and carotenoids such as lutein, zeaxanthin, astaxanthin, all B-vitamins, and minerals Zn and Se for simultaneously reducing oxidative and inflammatory damage. Since elevated levels of vascular endothelial growth factor (VEGF) are found in the wet ARMD and diabetic retinopathy, this mixture has ingredients, which reduce VEGF levels. Supplementation with this micronutrient mixture may delay the onset and progression of major eye diseases, and may improve the effectiveness of standard therapy.
\end{abstract}

Keywords: Eye diseases; Antioxidants; Free radicals; Pro-inflammatory cytokines; Protection

\section{Introduction}

The major vision impairments include refractive error, cataract, age-related macular degeneration (ARMD), glaucoma, and diabetic retinopathy, which can lead to blindness without an early intervention. There are approximately 1.3 million Americans who are legally blind. Visual impairment is one of the major health concerns nationally and internationally. In addition to the advancing age, the genetic, environmental, lifestyle, and dietary factors can influence the time of onset, progression, and severity of the eye diseases. The number of individuals with vision diseases and blindness is increasing because of increased lifespan in the USA. It is estimated that the number will continue to increase in future. Therefore it is imperative that an effective prevention and improved treatment strategies are developed.

Refractory error is caused by changes in the lens structure, while cataract is due to the opacity of the lens. Age-related macular degeneration is caused by damage to the retina and is characterized by the presence of Drusen (yellowish deposit) of varying sizes beneath the retinal pigment. Glaucoma is caused by reduction in fluid draining system resulting into increased pressure in the eye, while diabetic retinopathy is caused by damage to the vascular system in the eye.

Table 1 shows the prevalence of major eye diseases in the USA, such as refractive error, cataract.

\footnotetext{
* Corresponding author: Kedar N Prasad

Engage Global, inc. 245 El Faisan Drive, San Rafael, CA 94903.

Copyright (C) 2021 Author(s) retain the copyright of this article. This article is published under the terms of the Creative Commons Attribution Liscense 4.0.
} 
Table 1 Prevalence of major eye diseases in the USA (in million)

\begin{tabular}{|c|c|c|c|c|c|}
\hline Year & ARMD & Glaucoma & Cataract & Diabetic retinopathy & Refractive Error \\
\hline 2014 & 2.1 & 2.7 & 24 & 7.7 & 48.2 \\
\hline $2030 *$ & 3.7 & 4.3 & 38.7 & 11 & 59 \\
\hline
\end{tabular}

ARMD (Age-related macular degeneration) In 2014, refractive error includes 34.1 million myopia (near-sighted) and 14.1 million hyperopia (farsighted); In 2030, refractive error includes 39 million myopia and 20 million hyperopia. *Estimated value of prevalence; From the National Institute of Eye, NIH, Eye Disease Statistics, 2014

ARMD, glaucoma, and diabetic retinopathy. From these data, it appears that these vision impairments are of serious health concerns among adults 50 years and older. Table 2 shows the incidence of major eye diseases in ethnic groups in the USA. The incidence of ARMD was higher in non-Hispanic whites than Hispanics and African Americans, while glaucoma incidence in African Americans was higher than other ethnic groups. Hispanics have the highest incidence of cataract and diabetic retinopathy compared to other ethnic groups.

Table 2 Percent incidence of major eye diseases in ethnic groups in the USA

\begin{tabular}{|l|l|l|l|l|l|}
\hline Ethnic Groups & ARMD & Glaucoma & Cataract & Diabetic retinopathy & Others \\
\hline Non-Hispanic White & 28.1 & 2.3 & 42.2 & 4.7 & 22.7 \\
\hline Hispanic & 14.5 & 6.4 & 48.0 & 15.0 & 16.2 \\
\hline African Americans & 7.8 & 11.3 & 41.7 & 12 & 27.0 \\
\hline
\end{tabular}

Despite the use of corrective glasses, refractory error continues to progress requiring new glasses every few years. This is due to the fact that corrective glasses do not affect oxidative stress and inflammation that contribute to the development of this disease. Similarly, cataract can be treated effectively with surgery, which does not have any impact on the above cellular defects involved in the pathogenesis of opacity. The glaucoma, ARMD, and diabetic retinopathy are not easily treatable.

Increased oxidative stress and inflammation are major contributors to the initiation and progression of vision impairments. In cases, where abnormal proliferation of blood vessels is involved, increased levels of vascular endothelial growth factor (VEGF) contribute to the progression of such eye diseases. Therefore supplementation with antioxidants and an inhibitor of VEGF should be useful in such eye diseases.

The transparent vitreous body, which occupies $80 \%$ of eye volume, is composed of $98-99 \%$ of water, very small amounts of collagen fibers, glycosaminoglycan, non-collagenous proteins, and trace minerals. It also contains enzymatic and nonenzymatical antioxidants that protect vitreous body from oxidative damage $(1,2)$. Thus, it is important that as we grow older, the vitreous body of the eye should continue to be filled with sufficient amounts of antioxidants in order to delay the onset and progression of the major eye diseases.

In the normal eye, the vitreous body helps to maintain low oxygen concentration surrounding the lens (3). In a highly myopic eye, lens is exposed to increased oxidative stress due to the presence of high concentration of oxygen, which contributes to the degeneration of the vitreous body leading to an early onset of cataract (4). Increased oxidative stress causes hypermethylation of antioxidant enzymes genes that deceases the expression levels of antioxidant enzymes, which cause an early development of cataract in the myopic eye (5).

This review shows that enhanced oxidative stress and inflammation contribute to the age-related major eye diseases. Previous antioxidant approaches produced limited benefits in reducing the progression of certain eye diseases. The lack of the full spectrum of micronutrients in the experimental designs may have contributed to minimal beneficial effects Therefore a comprehensive mixture of micronutrients containing dietary and endogenous antioxidants together with lutein, zeaxanthin, and astaxanthin, all B-vitamins, Se and Zn, which may simultaneously reduce oxidative and inflammatory damage is proposed. Such a micronutrient mixture would delay the onset and progression of eye diseases, and may improve the efficacy of standard therapy. 


\section{Oxidative Stress and Inflammation in Major Eye Diseases}

Oxidative stress and inflammation is closely linked. If the oxidative damage of cells is not healed, chronic inflammatory responses occur. Such inflammatory responses release ROS, pro-inflammatory cytokines, complement proteins, and adhesion molecules that can cause cell death in the eyes.

\subsection{Refractory error}

Increased oxidative stress occurs in patients with myopia (6) and in all major eye diseases (7). High myopia is the leading cause of blindness. Levels of markers of oxidative stress, hepatocyte growth factor (HGF), and nitrite/nitrate ratio were elevated, while the levels of VEGF were reduced in the aqueous humor samples from patients with high myopia undergoing cataract surgery (8). Increased oxidative stress leads to increased inflammatory responses by producing enhanced amounts of NF-kB, a pro-inflammatory cytokine. The expression levels of c-Fos, NF-kB, IL-6, and TNF-alpha were also upregulated in the myopic eye, suggesting the role of chronic inflammation in the pathogenesis of myopia (9). High myopia causes thinning of retinal pigmented epithelial (RPE) cells leading to suppression of its function that results in depletion of VEGF in the aqueous humor (10).

\subsection{Age-related macular degeneration (ARMD)}

There are two forms of ARMD dry form and wet form. Dry form contributes to about $85-90 \%$ of all ARMD cases. In the wet form of ARMD abnormal blood vessels starts to grow beneath the retina (neovascularization) that allows fluid and blood to leak out giving the appearance of wet ARMD. It is the leading cause of loss of vision. Increase oxidative stress and inflammation cause degeneration of retinal epithelial cells leading to death of photoreceptors and ultimately loss of vision $(11,12)$. The macula is continuously exposed to high levels of oxidative stress. Tobacco smokers $(13,14)$ and high fat diet $(15,16)$, which generate excessive amounts of free radicals, further enhance oxidative damage to the macula accelerating the rate of progression of ARMD. Oxidative damage in the eye induces inflammatory responses which play an important role in the progression of ARMD. A recent review show that complement proteins and pro-inflammatory cytokines released from chronic inflammatory responses contribute to the pathogenesis of ARMD (17).

The wet ARMD is associated with increased levels of VEGF that cause neovascularization in the retina (18). Alphatocopheryl succinate), the most effective form of vitamin E (19), inhibits VEGF (20); therefore, this form of vitamin E, could be useful in the management of the eye diseases with an elevated level of VEGF.

\subsection{Cataract}

The incidence of cataract is high in countries with excessive sun light (21) which causes photochemical reaction in the eye producing excessive amounts of ROS that damages the lens (22). Increased oxidative stress is associated with the development of cataract (23-25)

\subsection{Glaucoma}

There are two forms of glaucoma open-angle glaucoma and close-angle glaucoma. Open-angle glaucoma is the most common form of glaucoma, which contributes to approximately $90 \%$ of all glaucoma cases. It develops gradually and the symptoms are difficult to detect. It had wide and open angle between iris and cornea. Normal-tension glaucoma is a form of open-angle glaucoma with normal eye pressure. About one-third of open-angle glaucoma represents this form of glaucoma. On the other hand, close-angle glaucoma has a close and narrow angle between iris and cornea (26). Excessive production of ROS plays an important role in the pathogenesis of primary open-angle glaucoma (POAG), which is a major contributor to the development of irreversible blindness worldwide $(27,28)$. The levels of malondialdehyde (MDA), a marker of oxidative stress, were elevated, while the levels of total antioxidant capacity declined in the blood and aqueous humor of patients with glaucoma (29). It was reported that production of ROS was caused by damage to the vascular system due to unstable blood flow resulting into an unstable oxygen supply (30). Furthermore, oxidative stress occurred primarily in the mitochondria of retinal ganglionic neurons and their axons causing the death of ganglion cells.

Glaucoma is characterized by degeneration of retinal ganglion cells and their axons in the optic nerve. Evidence for an early inflammatory responses initiated by activated astrocytes, microglia, and blood-derived immune cells are found at the optic nerve head $(\mathrm{ONH})$, suggesting a role of inflammation in the pathogenesis of glaucoma (31-33)

Increased intraocular pressure occurs due to a reduction in the drainage of axoplasmic fluid (29). In patients with glaucoma, increased production of aqueous humor caused an elevation of intraocular pressure that led to the death of retinal ganglion neurons (34). 


\subsection{Diabetic retinopathy}

Diabetic retinopathy is considered a microvascular complication of diabetes, which is the leading cause of blindness. Increased oxidative stress plays an important role in the onset and progression of diabetic retinopathy (35-39). Increased markers of inflammation are also found in patients with diabetic retinopathy (40-42). Activated retinal microglia migrate to the site of inflammation and produce pro-inflammatory cytokines, ROS, nitric oxide, glutamate , and proteases, which contribute to the degeneration and eventually the death of retinal ganglion cells (43-45). In addition to increased oxidative stress and chronic inflammation, enhanced the levels of VEGF, which contributes to both vascular permeability and angiogenesis, occurs in rodent models (46)

\section{Role of Carotenoids alone in the Management of Major Eye Diseases}

Several studies have been performed in determining the benefits of one or more carotenoids in certain eye diseases. These studies are described here.

\subsection{Astaxanthin in animal studies}

Astaxanthin, a carotenoid, accumulates selectively in the eye. It protects retinal cells in vitro and in mice against oxidative stress (47). It also reduced oxidative and inflammatory damage in the retinal cells of diabetic rats (48). Astaxanthin decreases oxidative stress and inflammation, improves immune response $(49,50)$, reduces apoptosis in retinal ganglion cells, and retinal pigmented epithelial cells in rodents $(51,52)$.

\subsection{Lutein and zeaxanthin in epidemiologic studies}

The analysis from the Growing Up in Singapore towards Healthy Outcomes (GUSTO) cohort showed that high levels of maternal plasma concentration of carotenoids lutein and zeaxanthin were associated with improved visual acuity of the offspring (53). Extensive epidemiologic studies have revealed conflicting results on the beneficial effects of antioxidants in the management of major eye diseases. This review has focused on only intervention investigation with one or more micronutrients.

\section{Individual Antioxidants or Minerals in Eye Diseases}

The use of individual antioxidants or minerals produced inconsistent results in patients with ARMD (54).

\section{Role of a Mixture of Dietary Antioxidants with or without Carotenoids in Eye Diseases}

These studies and their limitation are describe below under each eye disease

\subsection{Refractory error}

\subsubsection{A mixture of dietary antioxidants together with carotenoids in refractory errors in dogs}

Like human, dogs also show age-related decline in vision. Treatment with dietary antioxidants (vitamin C, vitamin E. and beta-carotene) together with eye carotenoids (lutein, zeaxanthin, and astaxanthin) for a period of six months slowed down the development of refractory error and improved retinal and visual function in the dogs (55). This formula lacks endogenous antioxidants, vitamin D3 as well as B-vitamins and minerals selenium and Zn. Therefore such micronutrient mixture may not produce desired benefits in human eye disease.

\subsection{Age-related macular degeneration (ARMD)}

\subsubsection{A mixture of dietary antioxidants and zinc in $A R M D$}

In the initial AREDS (Age-Related Eye Disease Study), oral supplementation with a mixture of vitamin C, vitamin E, betacarotene, and zinc modestly decreased the risk of progression of ARMD and vision loss (56). This micronutrient mixture lacks endogenous antioxidants, vitamin D3, carotenoids lutein, zeaxanthin and astaxanthin, all B-vitamins, and selenium and zinc; therefore, may not produce optimal benefits.

In the AREDS2, a mixture of dietary antioxidants (high-dose vitamin C and vitamin E) together with lutein and zeaxanthin and minerals zinc and copper modestly reduced the progression of ARMD. Addition of DHA (docosahexaenoic acid) plus EPA (eicosapentaenoic acid) to this formula showed no further benefit (57). Inclusion of beta-carotene increased the risk lung cancers among smokers. Another study reported that lutein and zeaxanthin 
without beta-carotene would be appropriate in reducing the risk of progression of ARMD (58). This micronutrient mixture lacks other dietary and endogenous antioxidants, vitamin D3, astaxanthin, B-vitamins, Se and Zn. The addition of astaxanthin is essential because it exhibits the most powerful antioxidant and anti-inflammation activities compared to other carotenoids (59). Unlike most antioxidants, which protect inner layer or outer layer of the cellular membrane against oxidative damage, astaxanthin protects both layers against such damage $(60,61)$. In addition, high-dose of zinc (80 $\mathrm{mg}$ ) in this micronutrient mixture may induce copper deficiency by reducing the absorption of copper from the intestine $(62,63)$. Copper in this formula may also interact with vitamin $\mathrm{C}$ to generate excessive amounts of free radicals (64). Therefore, this micronutrient mixture may not produce desired benefits in improving the management of eye diseases.

\subsubsection{A mixture of B-vitamins in Eye Diseases}

Daily supplementation with a mixture of certain B-vitamins, such as folic acid, vitamin-B6, and vitamin-B12 reduced the risk of ARMD in women (65). This mixture lacks all dietary and endogenous antioxidants, vitaminD3, carotenoids, and minerals Se and Zn.

\section{Cataract}

\subsection{One or a mixture of antioxidants in Catarct}

Supplementation with vitamin C protected light-induced damage to the ocular lens (66). The Antioxidant in Prevention of Cataract (APC) Study with a follow-up period of 5 years revealed that a mixture of vitamin C, vitamin E and betacarotene did not affect the progression of cataract in the population of South India (67). Supplementation of betacarotene alone was ineffective in reducing the progression of cataract (68). Antioxidants/mineral supplement decreased the risk (69), and attenuated the progression of cataract (70). Supplementation with a mixture of vitamin E, vitamin $\mathrm{C}$, and beta-carotene for a period of 3 years produced a small rate of reduction in the progression of cataract (71).

\section{Glaucoma}

\subsection{A mixture of antioxidants, omega-3-fatty acids, and minerals in Glaucoma}

Glaucoma and dry eye disorder (DED) frequently appear as a comorbid. Open-angle glaucoma had elevated levels of TNF-alpha, IL-6, and VEGF compared to non-severe DED glaucoma, and it had higher levels of Il-6 than control subjects. Oral administration of a mixture of antioxidants (vitamin A, vitamin C, vitamin E, and glutathione), Omega 3 fatty acids DHA (decosahexaenoic acid), EPA (eicosahexaenoic acid), DPA (decosapentaenoic acid), minerals (zinc, copper, manganese, and selenium), and tyrosine and cystenine reduced IL-6 and TNF-alpha in patients with open-angle glaucoma (72). This micronutrient mixture lacks endogenous antioxidants, carotenoids, and B-vitamins. Copper interacts with vitamin $C$ to generate excessive amounts of free radicals. Studies on animal models of glaucoma suggest that lutein protects retina from oxidative damage (73).

\section{Diabetic Retinopathy}

\subsection{A single antioxidant or a mixture of dietary antioxidants in diabetic retinopathy}

Because of involvement of oxidative stress and inflammation in diabatic retinopathy, animal and human studies suggest that antioxidants may be helpful in prevention and improved management of this eye disease (74). A mitochondrial antioxidant enzyme Mn-SOD (manganese-dependent superoxide dismutase) is impaired in diabetic retinopathy. Therefore activation of this antioxidant enzyme may prevent mitochondrial dysfunction by scavenging superoxide. Supplementation with alpha-lipoic acid, a co-factor of Mn-SOD, prevented apoptosis of retinal capillary cells and the development of diabetic retinopathy in rats (37). A mixture of vitamin C, vitamin E, and beta-carotene did not reduce the risk of diabetic retinopathy in humans (75). Vitamin B1 (thiamine) treatment protected retinal pericytes against apoptosis in experimental model (76) 


\section{Rationale for Administering a Comprehensive Mixture of Micronutrients in the Eye Diseases}

\subsection{Failure of single antioxidants}

Some potential reasons for the failure of a single antioxidant to yield expected benefits that were observed in animal models, but not in humans, are described here.

- Eye is exposed to high levels of ROS all the time. Administration of a single antioxidant in a high oxidative environment of the eye would be oxidized, which then would act as a pro-oxidant rather than as an antioxidant.

- Different antioxidants are distributed differently and in different amounts in the sub-cellular compartments of the cells of the eye, all of which must be protected. Administration of a single antioxidant cannot accumulate in all parts of the cell in sufficient amounts to provide an adequate protection against oxidative damage.

- Vitamin $\mathrm{E}$ is more effective scavenger of free radicals in reduced oxygen pressure, whereas beta-carotene and vitamin A are more effective in higher oxygen pressure of the cells (77). Since eye pressure varies in some eye diseases such as glaucoma, administration of one antioxidant may not provide adequate protection throughout the eye.

- Elevation of both antioxidant enzymes, dietary and endogenous antioxidant compounds as well as carotenoids lutein, zeaxanthin, astaxanthin are needed to achieve maximal protection against oxidative damage in the entire eye. This is due to the fact that they act by different mechanisms. Antioxidant compounds neutralize free radicals by donating electrons to those atoms in the molecules with unpaired electrons, whereas antioxidant enzymes destroy $\mathrm{H} 202$ by catalysis, converting them to harmless molecules such as water and oxygen. Administration of a single antioxidant alone cannot achieve this goal.

- Administration of a single antioxidant cannot protect both the aqueous and lipid compartments of the cells in the eye against oxidative damage.

- Different antioxidants increase the production of different protective proteins in the cells by altering the expression of different microRNAs (78). For example, some antioxidants can activate Nrf2 by upregulating miR200a that inhibits its target protein Keap1, whereas others activate Nrf2 by downregulating miR-21 that binds with 3'-UTR Nrf2 mRNA (79). Thus, different antioxidants activate Nrf2 (Nuclear Factor-Erythroid-2- Related Factor 2) by different mechanisms. Administration of a single antioxidant cannot accomplish the above objective.

\subsection{Problems associated with previous micronutrient approaches}

As discussed earlier, various mixture of micronutrients used in previous eye disease studies produced only modest reduction in progression of some eye diseases. This could be attributed to the lack of the full spectrum of micronutrients in mixture, which can simultaneously decrease oxidative and inflammatory damage in the eye.

\section{How to simultaneously Reduce Oxidative Stress and Inflammation in the Eyes}

In order to reduce oxidative stress and inflammation at the same time, it is essential to simultaneously enhance the levels of antioxidant enzymes and dietary and endogenous antioxidant compounds (80). Oral supplementation with a mixture of antioxidants can increase the levels of dietary and endogenous antioxidant compounds; however, enhancing the levels of antioxidant enzymes require an activation of a nuclear transcriptional factor Nrf2. A brief description of the activation of Nrf2 processes is presented here.

\subsection{Activation Processes of Nrf2}

Under normal physiological conditions, reactive oxygen species (ROS) is required to activate Nrf2. Activated Nrf2 dissociates itself from Keap1- CuI-Rbx1 complex in the cytoplasm and migrates to the nucleus where it heterodimerizes with a small Maf protein and binds with ARE (antioxidant response element) leading to increased transcription of cytoprotective enzymes including antioxidant enzymes (81-85).

During the prolonged oxidative stress commonly observed in human chronic diseases, activation of Nrf2 becomes resistant to ROS (86-88). This is evidenced by the fact that increased oxidative stress continues to occur in chronic diseases despite the presence of Nrf2. However, some antioxidants such as alpha-tocopherol and genistein $(89,90)$, alpha-lipoic acid (91), curcumin (92), resveratrol (93, 94), omega-3-fatty acids, (95, 96), glutathione (97), nacetylcysteine (98), and coenzyme Q10 (99) can activate this ROS-resistant Nrf2. 
Activation of Nrf2 alone is not adequate to enhance the levels of antioxidant enzymes. Activated Nrf2 must then bind to ARE in order to promote the transcription of genes coding for antioxidant enzymes.

\subsection{Activated Nrf2 and antioxidant compounds attenuate inflammation}

It has been reported that activation of Nrf2 decreases oxidative stress as well inflammation $(100,101)$. Many antioxidant compounds also attenuate inflammation (102-107).

\section{Proposed Mixture of Micronutrients may Reduce the Onset and Progression of Major Eye Diseases.}

A comprehensive mixture of micronutrients containing vitamin A, mixed carotenoids, vitamin C, alpha-tocopheryl acetate, alpha-tocopheryl succinate, vitamin D3, alpha-lipoic acid, N-acetylcysteine, coenzyme Q10, curcumin, resveratrol, lutein, zeaxanthin, astaxanthin, all B-vitamins, and minerals selenium, and zinc for delaying the onset and progression of major eye diseases is proposed. This mixture would increase the levels of antioxidant enzymes by activating the ROS-resistant Nrf2 and enhancing the levels of dietary and endogenous antioxidant compounds. Such a micronutrient mixture may optimally and simultaneously reduce oxidative stress and chronic inflammation, and thereby, provide a maximal protection against oxidative and inflammatory damage in the eye. This micronutrient mixture may delay the onset and progression of major eye diseases.

\section{Conclusion}

The major eye diseases, such as refractive error, cataract, age-related macular degeneration (ARMD), glaucoma, and diabetic retinopathy are serious health concerns for people 50 years and older. They can lead to blindness without early intervention. The current practices for improving the eye-sight do not address the issue of increased levels of oxidative stress and inflammation that contribute to the onset and progression of these eye diseases. Therefore, supplementation with antioxidants could be useful in reducing the risk of these diseases. Studies suggest that supplementation with dietary antioxidants with or without lutein, zeaxanthin, omega-3-fatty acids has reduced somewhat the progression of certain eye diseases. However, these mixture of micronutrients lacked several ingredients that are necessary for simultaneously reducing oxidative stress and inflammation in the eye. The rationale for using a comprehensive mixture of micronutrients containing dietary and endogenous antioxidants, vitamin D3, lutein, zeaxanthin, astaxanthin, all Bvitamins, and minerals $\mathrm{Zn}$ and Se for simultaneously reducing oxidative and inflammatory damages is proposed. This mixture also contains d-alpha-tocopheryl succinate that can reduce the levels of vascular endothelial growth factor (VEGF) in eye diseases, such as wet (ARMD) and diabetic retinopathy, which have elevated levels of VEGF. Supplementation with this proposed micronutrient mixture may delay the onset and progression of major eye diseases, and may improve the efficacy of standard therapy. Pre-clinical and clinical studies to test the efficacy of this micronutrient mixture for reducing the risk of development and progression of each major eye disease are recommended.

\section{Compliance with ethical standards}

\section{Disclosure of conflict of interest}

The author is Chief Scientific Officer of Engage Global, inc. of Utah. This company sells nutritional products to consumers.

\section{References}

[1] Ankamah E, Sebag J, Ng E, Nolan JM. Vitreous Antioxidants, Degeneration, and Vitreo-Retinopathy: Exploring the Links. Antioxidnats -Basel. 2020; 9(8).

[2] Bishop P. The biochemical structure of mammalian vitreous. Eye (Lond). 1996; 10(6): 664-70.

[3] Beebe DC, Holekamp NM, Siegfried C, Shui YB. Vitreoretinal influences on lens function and cataract. Philos Trans R Soc Lond B Biol Sci. 2011; 366(1568): 1293-300.

[4] Morita H, Funata M, Tokoro T. A clinical study of the development of posterior vitreous detachment in high myopia. Retina. 1995; 15(2): 117-24.

[5] Zhu X, Li D, Du Y, He W, Lu Y. DNA hypermethylation-mediated downregulation of antioxidant genes contributes to the early onset of cataracts in highly myopic eyes. Redox Biol. 2018; 19: 179-89. 
[6] Francisco BM, Salvador M, Amparo N. Oxidative stress in myopia. Oxid Med Cell Longev. $2015 ; 750637$.

[7] Cejka C, Cejkova J. Oxidative stress to the cornea, changes in corneal optical properties, and advances in treatment of corneal oxidative injuries. Oxid Med Cell Longev. 2015; 591530.

[8] Merida S, Villar VM, Navea A, Desco C, Sancho-Tello M, Peris C, et al. Imbalance Between Oxidative Stress and Growth Factors in Human High Myopia. Front Physiol. 2020; 11: 463.

[9] Lin HJ, Wei CC, Chang CY, Chen TH, Hsu YA, Hsieh YC, et al. Role of Chronic Inflammation in Myopia Progression: Clinical Evidence and Experimental Validation. EBioMedicine. 2016; 10: 269-81.

[10] Shin YJ, Nam WH, Park SE, Kim JH, Kim HK. Aqueous humor concentrations of vascular endothelial growth factor and pigment epithelium-derived factor in high myopic patients. Mol Vis. 2012; 18: 2265-70.

[11] Kauppinen A, Paterno JJ, Blasiak J, Salminen A, Kaarniranta K. Inflammation and its role in age-related macular degeneration. Cell Mol Life Sci. 2016; 73(9): 1765-86.

[12] Datta S, Cano M, Ebrahimi K, Wang L, Handa JT. The impact of oxidative stress and inflammation on RPE degeneration in non-neovascular AMD. Prog Retin Eye Res. 2017; 60: 201-18.

[13] Rangasamy T, Cho CY, Thimmulappa RK, Zhen L, Srisuma SS, Kensler TW, et al. Genetic ablation of Nrf2 enhances susceptibility to cigarette smoke-induced emphysema in mice. J Clin Invest. 2004; 114(9): 1248-59.

[14] Smith CJ, Hansch C. The relative toxicity of compounds in mainstream cigarette smoke condensate. Food Chem Toxicol. 2000; 38(7): 637-46.

[15] Chiu CJ, Chang ML, Zhang FF, Li T, Gensler G, Schleicher M, et al. The relationship of major American dietary patterns to age-related macular degeneration. Am J Ophthalmol. 2014; 158(1): 118-27 e1.

[16] Seddon JM, Cote J, Rosner B. Progression of age-related macular degeneration: association with dietary fat, transunsaturated fat, nuts, and fish intake. Arch Ophthalmol. 2003; 121(12): 1728-37.

[17] Knickelbein JE, Chan CC, Sen HN, Ferris FL, Nussenblatt RB. Inflammatory Mechanisms of Age-related Macular Degeneration. Int Ophthalmol Clin. 2015; 55(3): 63-78.

[18] Grossniklaus HE, Ling JX, Wallace TM, Dithmar S, Lawson DH, Cohen C, et al. Macrophage and retinal pigment epithelium expression of angiogenic cytokines in choroidal neovascularization. Mol Vis. 2002; 8: 119-26.

[19] Prasad KN, Kumar B, Yan XD, Hanson AJ, Cole WC. Alpha-tocopheryl succinate, the most effective form of vitamin E for adjuvant cancer treatment: a review. J Am Coll Nutr. 2003; 22(2): 108-17.

[20] Malafa MP, Fokum FD, Smith L, Louis A. Inhibition of angiogenesis and promotion of melanoma dormancy by vitamin E succinate. Ann Surg Oncol. 2002; 9(10): 1023-32.

[21] Resnikoff S, Pascolini D, Etya'ale D, Kocur I, Pararajasegaram R, Pokharel GP, et al. Global data on visual impairment in the year 2002. Bull World Health Organ. 2004; 82(11): 844-51.

[22] Varma SD, Chand D, Sharma YR, Kuck JF, Jr., Richards RD. Oxidative stress on lens and cataract formation: role of light and oxygen. Curr Eye Res. 1984; 3(1): 35-57.

[23] Chang D, Zhang X, Rong S, Sha Q, Liu P, Han T, et al. Serum antioxidative enzymes levels and oxidative stress products in age-related cataract patients. Oxid Med Cell Longev. 2013; 587826.

[24] Braakhuis AJ, Donaldson CI, Lim JC, Donaldson PJ. Nutritional Strategies to Prevent Lens Cataract: Current Status and Future Strategies. Nutrients. 2019; 11(5).

[25] Liu XF, Hao JL, Xie T, Malik TH, Lu CB, Liu C, et al. Nrf2 as a target for prevention of age-related and diabetic cataracts by against oxidative stress. Aging Cell. 2017; 16(5): 934-42.

[26] Institute NNE. types of glaucoma. In: Insitute N, editor. Bethesda MD: NIH. 2020.

[27] Izzotti A, Bagnis A, Sacca SC. The role of oxidative stress in glaucoma. Mutat Res. 2006; 612(2): 105-14.

[28] McMonnies C. Reactive oxygen species, oxidative stress, glaucoma and hyperbaric oxygen therapy. J Optom. 2018; 11(1): 3-9.

[29] Nucci C, Di Pierro D, Varesi C, Ciuffoletti E, Russo R, Gentile R, et al. Increased malondialdehyde concentration and reduced total antioxidant capacity in aqueous humor and blood samples from patients with glaucoma. Mol Vis. 2013; 19: 1841-6. 
[30] Flammer J, Konieczka K, Flammer AJ. The primary vascular dysregulation syndrome: implications for eye diseases. EPMA J. 2013; 4(1): 14.

[31] Howell GR, Soto I, Zhu X, Ryan M, Macalinao DG, Sousa GL, et al. Radiation treatment inhibits monocyte entry into the optic nerve head and prevents neuronal damage in a mouse model of glaucoma. J Clin Invest. 2012; 122(4): 1246-61.

[32] Soto I, Howell GR. The complex role of neuroinflammation in glaucoma. Cold Spring Harb Perspect Med. 2014; $4(8)$.

[33] Tezel G. Immune regulation toward immunomodulation for neuroprotection in glaucoma. Curr Opin Pharmacol. 2013; 13(1): 23-31.

[34] Kumar DM, Agarwal N. Oxidative stress in glaucoma: a burden of evidence. J Glaucoma. 2007; 16(3): $334-43$.

[35] Kowluru RA, Chan PS. Oxidative stress and diabetic retinopathy. Exp Diabetes Res. 2007; 43603.

[36] Rodriguez-Carrizalez AD, Castellanos-Gonzalez JA, Martinez-Romero EC, Miller-Arrevillaga G, Villa-Hernandez D, Hernandez-Godinez PP, et al. Oxidants, antioxidants and mitochondrial function in non-proliferative diabetic retinopathy. J Diabetes. 2014; 6(2): 167-75.

[37] Santos JM, Mohammad G, Zhong Q, Kowluru RA. Diabetic retinopathy, superoxide damage and antioxidants. Curr Pharm Biotechnol. 2011; 12(3): 352-61.

[38] Joanna K, Katarzyna, K-K., Hassa, Y. A-E. The role of oxidative stress in the pathogenesis of eye diseases: Current and a dual role of physical activity. Min-Rev Med Chem. 2016; 16: 241,57.

[39] Kang Q, Yang C. Oxidative stress and diabetic retinopathy: Molecular mechanisms, pathogenetic role and therapeutic implications. Redox Biol. 2020; 37: 101799.

[40] Al-Kharashi AS. Role of oxidative stress, inflammation, hypoxia and angiogenesis in the development of diabetic retinopathy. Saudi J Ophthalmol. 2018; 32(4): 318-23.

[41] Joussen AM, Poulaki V, Le ML, Koizumi K, Esser C, Janicki H, et al. A central role for inflammation in the pathogenesis of diabetic retinopathy. FASEB J. 2004; 18(12): 1450-2.

[42] Brucklacher RM, Patel, K.M., VanGuilder, H.D., Bixler, G.V. et al. Whole genome assessment of the retinal response to diabetic reveals a progressive neurovascular inflammatory response. BMC Med Genom. 2008; $13: 26$.

[43] Zeng HY, Green WR, Tso MO. Microglial activation in human diabetic retinopathy. Arch Ophthalmol. 2008; 126(2): 227-32.

[44] Grigsby JG, Cardona SM, Pouw CE, Muniz A, Mendiola AS, Tsin AT, et al. The role of microglia in diabetic retinopathy. J Ophthalmol. 2014; 705783.

[45] Rubsam A, Parikh S, Fort PE. Role of Inflammation in Diabetic Retinopathy. Int J Mol Sci. 2018; 19(4).

[46] Miller JW, Adamis AP, Shima DT, D'Amore PA, Moulton RS, O'Reilly MS, et al. Vascular endothelial growth factor/vascular permeability factor is temporally and spatially correlated with ocular angiogenesis in a primate model. Am J Pathol. 1994; 145(3): 574-84.

[47] Nakajima Y, Inokuchi Y, Shimazawa M, Otsubo K, Ishibashi T, Hara H. Astaxanthin, a dietary carotenoid, protects retinal cells against oxidative stress in-vitro and in mice in-vivo. J Pharm Pharmacol. 2008; 60(10): $1365-74$.

[48] Yeh PT, Huang HW, Yang CM, Yang WS, Yang CH. Astaxanthin Inhibits Expression of Retinal Oxidative Stress and Inflammatory Mediators in Streptozotocin-Induced Diabetic Rats. PLoS One. 2016; 11(1): e0146438.

[49] Macedo RC, Bolin AP, Marin DP, Otton R. Astaxanthin addition improves human neutrophils function: in vitro study. Eur J Nutr. 2010; 49(8): 447-57.

[50] Park JS, Chyun JH, Kim YK, Line LL, Chew BP. Astaxanthin decreased oxidative stress and inflammation and enhanced immune response in humans. Nutr Metab (Lond). 2010; 7: 18.

[51] Dong LY, Jin J, Lu G, Kang XL. Astaxanthin attenuates the apoptosis of retinal ganglion cells in db/db mice by inhibition of oxidative stress. Mar Drugs. 2013; 11(3): 960-74.

[52] Yamagishi R, Aihara M. Neuroprotective effect of astaxanthin against rat retinal ganglion cell death under various stresses that induce apoptosis and necrosis. Mol Vis. 2014; 20: 1796-805. 
[53] Lai JS, Veetil VO, Lanca C, Lee BL, Godfrey KM, Gluckman PD, et al. Maternal Lutein and Zeaxanthin Concentrations in Relation to Offspring Visual Acuity at 3 Years of Age: The GUSTO Study. Nutrients. 2020; 12(2).

[54] Gorusupudi A, Nelson K, Bernstein PS. The Age-Related Eye Disease 2 Study: Micronutrients in the Treatment of Macular Degeneration. Adv Nutr. 2017; 8(1): 40-53.

[55] Wang W, Hernandez J, Moore C, Jackson J, Narfstrom K. Antioxidant supplementation increases retinal responses and decreases refractive error changes in dogs. J Nutr Sci. 2016; 5: e18.

[56] Group A. A randomized, placebo-controlled, clinical trial of high-dose supplementation with vitamin C and E, beta-carotene, and zinc for age-related macular degeneration and vission loss. AREDS Report No 8. Arch Ophthalmol. 2001; 119: 1417-36.

[57] Group C-A-REDSR. Lutein +zeaxanthin and omega-3-fatty acids for age-related macular degeneration: the AgeRelated Eye Disease Study 2 Reserach group (AREDS2) randomized clinical trial. JAMA. 2013; 309: $2005-15$.

[58] Group A-REDSAR. Secondary analysis of the effects of lutein/zeaxanthin on age related macular degeneration progression: AREDS2 report No.3. JAMA Ophthalmol. 2014; 132: 142-9.

[59] Naguib YM. Antioxidant activities of astaxanthin and related carotenoids. J Agric Food Chem. 2000; 48(4): 11504.

[60] Fakhri S, Abbaszadeh F, Dargahi L, Jorjani M. Astaxanthin: A mechanistic review on its biological activities and health benefits. Pharmacol Res. 2018; 136: 1-20.

[61] Kidd P. Astaxanthin, cell membrane nutrient with diverse clinical benefits and anti-aging potential. Altern Med Rev. 2011; 16(4): 355-64.

[62] Appenzeller-Herzog C, Mathes T, Heeres MLS, Weiss KH, Houwen RHJ, Ewald H. Comparative effectiveness of common therapies for Wilson disease: A systematic review and meta-analysis of controlled studies. Liver Int. 2019; 39(11): 2136-52.

[63] Afrin LB. Fatal copper deficiency from excessive use of zinc-based denture adhesive. Am J Med Sci. 2010; 340(2): 164-8.

[64] Rabovsky AB, Komarov AM, Ivie JS, Buettner GR. Minimization of free radical damage by metal catalysis of multivitamin/multimineral supplements. Nutr J. 2010; 9: 61.

[65] Gopinath B, Flood VM, Rochtchina E, Wang JJ, Mitchell P. Homocysteine, folate, vitamin B-12, and 10-y incidence of age-related macular degeneration. Am J Clin Nutr. 2013; 98(1): 129-35.

[66] Varma SD, Kumar S, Richards RD. Light-induced damage to ocular lens cation pump: prevention by vitamin C. Proc Natl Acad Sci U S A. 1979; 76(7): 3504-6.

[67] Gritz DC, Srinivasan M, Smith SD, Kim U, Lietman TM, Wilkins JH, et al. The Antioxidants in Prevention of Cataracts Study: effects of antioxidant supplements on cataract progression in South India. Br J Ophthalmol. 2006; 90(7): 847-51.

[68] Christen WG, Manson JE, Glynn RJ, Gaziano JM, Sperduto RD, Buring JE, et al. A randomized trial of beta carotene and age-related cataract in US physicians. Arch Ophthalmol. 2003; 121(3): 372-8.

[69] Zhao LQ, Li LM, Zhu H, The Epidemiological Evidence-Based Eye Disease Study Research Group EY. The effect of multivitamin/mineral supplements on age-related cataracts: a systematic review and meta-analysis. Nutrients. 2014; 6(3): 931-49.

[70] Sperduto RD, Hu TS, Milton RC, Zhao JL, Everett DF, Cheng QF, et al. The Linxian cataract studies. Two nutrition intervention trials. Arch Ophthalmol. 1993; 111(9): 1246-53.

[71] Chylack LT, Jr., Brown NP, Bron A, Hurst M, Kopcke W, Thien U, et al. The Roche European American Cataract Trial (REACT): a randomized clinical trial to investigate the efficacy of an oral antioxidant micronutrient mixture to slow progression of age-related cataract. Ophthalmic Epidemiol. 2002; 9(1): 49-80.

[72] Galbis-Estrada C, Pinazo-Duran MD, Cantu-Dibildox J, Marco-Ramirez C, Diaz-Llopis M, Benitez-del-Castillo J. Patients undergoing long-term treatment with antihypertensive eye drops responded positively with respect to their ocular surface disorder to oral supplementation with antioxidants and essential fatty acids. Clin Interv Aging. 2013; 8: 711-9.

[73] Li SY, Lo AC. Lutein protects RGC-5 cells against hypoxia and oxidative stress. Int J Mol Sci. 2010; 11(5): $2109-17$. 
[74] Williams M, Hogg RE, Chakravarthy U. Antioxidants and diabetic retinopathy. Curr Diab Rep. 2013; $13(4): 481-7$.

[75] Mayer-Davis EJ, Bell RA, Reboussin BA, Rushing J, Marshall JA, Hamman RF. Antioxidant nutrient intake and diabetic retinopathy: the San Luis Valley Diabetes Study. Ophthalmology. 1998; 105(12): 2264-70.

[76] Hammes HP, Du X, Edelstein D, Taguchi T, Matsumura T, Ju Q, et al. Benfotiamine blocks three major pathways of hyperglycemic damage and prevents experimental diabetic retinopathy. Nat Med. 2003; 9(3): 294-9.

[77] Vile GF, Winterbourn CC. Inhibition of adriamycin-promoted microsomal lipid peroxidation by beta-carotene, alpha-tocopherol and retinol at high and low oxygen partial pressures. FEBS Lett. 1988; 238(2): 353-6.

[78] Prasad KN, Bondy SC. MicroRNAs in Hearing Disorders: Their Regulation by Oxidative Stress, Inflammation and Antioxidants. Front Cell Neurosci. 2017; 11: 276.

[79] Wu H, Kong L, Tan Y, Epstein PN, Zeng J, Gu J, et al. C66 ameliorates diabetic nephropathy in mice by both upregulating NRF2 function via increase in miR-200a and inhibiting miR-21. Diabetologia. 2016.

[80] Prasad KN. Simultaneous activation of Nrf2 and elevation of antioxidant compounds for reducing oxidative stress and chronic inflammation in human Alzheimer's disease. Mech Ageing Dev. 2016; 153: 41-7.

[81] Itoh K, Chiba T, Takahashi S, Ishii T, Igarashi K, Katoh Y, et al. An Nrf2/small Maf heterodimer mediates the induction of phase II detoxifying enzyme genes through antioxidant response elements. Biochemical and biophysical research communications. 1997; 236(2): 313-22.

[82] Chan K, Han XD, Kan YW. An important function of Nrf2 in combating oxidative stress: detoxification of acetaminophen. Proceedings of the National Academy of Sciences of the United States of America. 2001; 98(8): 4611-6.

[83] Hayes JD, Chanas SA, Henderson CJ, McMahon M, Sun C, Moffat GJ, et al. The Nrf2 transcription factor contributes both to the basal expression of glutathione S-transferases in mouse liver and to their induction by the chemopreventive synthetic antioxidants, butylated hydroxyanisole and ethoxyquin. Biochemical Society transactions. 2000; 28(2): 33-41.

[84] Williamson TP, Johnson DA, Johnson JA. Activation of the Nrf2-ARE pathway by siRNA knockdown of Keap1 reduces oxidative stress and provides partial protection from MPTP-mediated neurotoxicity. Neurotoxicology. $2012 ; 33(3): 272-9$.

[85] Jaramillo MC, Zhang DD. The emerging role of the Nrf2-Keap1 signaling pathway in cancer. Genes Dev. 2013; 27(20): 2179-91.

[86] Ramsey CP, Glass CA, Montgomery MB, Lindl KA, Ritson GP, Chia LA, et al. Expression of Nrf2 in neurodegenerative diseases. J Neuropathol Exp Neurol. 2007; 66(1): 75-85.

[87] Chen PC, Vargas MR, Pani AK, Smeyne RJ, Johnson DA, Kan YW, et al. Nrf2-mediated neuroprotection in the MPTP mouse model of Parkinson's disease: Critical role for the astrocyte. Proc Natl Acad Sci U S A. 2009; 106(8): 29338.

[88] Lastres-Becker I, Ulusoy A, Innamorato NG, Sahin G, Rabano A, Kirik D, et al. alpha-Synuclein expression and Nrf2 deficiency cooperate to aggravate protein aggregation, neuronal death and inflammation in early-stage Parkinson's disease. Hum Mol Genet. 2012; 21(14): 3173-92.

[89] Xia J, Duan Q, Ahmad A, Bao B, Banerjee S, Shi Y, et al. Genistein inhibits cell growth and induces apoptosis through up-regulation of miR-34a in pancreatic cancer cells. Curr Drug Targets. 2012; 13(14): 1750-6.

[90] Xi YD, Yu HL, Ding J, Ma WW, Yuan LH, Feng JF, et al. Flavonoids protect cerebrovascular endothelial cells through Nrf2 and PI3K from beta-amyloid peptide-induced oxidative damage. Current neurovascular research. 2012; 9(1): 32-41.

[91] Suh JH, Shenvi SV, Dixon BM, Liu H, Jaiswal AK, Liu RM, et al. Decline in transcriptional activity of Nrf2 causes agerelated loss of glutathione synthesis, which is reversible with lipoic acid. Proceedings of the National Academy of Sciences of the United States of America. 2004; 101(10): 3381-6.

[92] Trujillo J, Chirino YI, Molina-Jijon E, Anderica-Romero AC, Tapia E, Pedraza-Chaverri J. Renoprotective effect of the antioxidant curcumin: Recent findings. Redox biology. 2013; 1(1): 448-56.

[93] Steele ML, Fuller S, Patel M, Kersaitis C, Ooi L, Munch G. Effect of Nrf2 activators on release of glutathione, cysteinylglycine and homocysteine by human U373 astroglial cells. Redox biology. 2013; 1(1): 441-5. 
[94] Kode A, Rajendrasozhan S, Caito S, Yang SR, Megson IL, Rahman I. Resveratrol induces glutathione synthesis by activation of Nrf2 and protects against cigarette smoke-mediated oxidative stress in human lung epithelial cells. American journal of physiology Lung cellular and molecular physiology. 2008; 294(3): L478-88.

[95] Gao L, Wang J, Sekhar KR, Yin H, Yared NF, Schneider SN, et al. Novel n-3 fatty acid oxidation products activate Nrf2 by destabilizing the association between Keap1 and Cullin3. The Journal of biological chemistry. 2007; 282(4): 2529-37.

[96] Saw CL, Yang AY, Guo Y, Kong AN. Astaxanthin and omega-3 fatty acids individually and in combination protect against oxidative stress via the Nrf2-ARE pathway. Food and chemical toxicology : an international journal published for the British Industrial Biological Research Association. 2013; 62: 869-75.

[97] Song J, Kang SM, Lee WT, Park KA, Lee KM, Lee JE. Glutathione protects brain endothelial cells from hydrogen peroxide-induced oxidative stress by increasing nrf2 expression. Exp Neurobiol. 2014; 23(1): 93-103.

[98] Ji L, Liu R, Zhang XD, Chen HL, Bai H, Wang X, et al. N-acetylcysteine attenuates phosgene-induced acute lung injury via up-regulation of Nrf2 expression. Inhalation toxicology. 2010; 22(7): 535-42.

[99] Choi HK, Pokharel YR, Lim SC, Han HK, Ryu CS, Kim SK, et al. Inhibition of liver fibrosis by solubilized coenzyme Q10: Role of Nrf2 activation in inhibiting transforming growth factor-beta1 expression. Toxicology and applied pharmacology. 2009; 240(3): 377-84.

[100] Kim J, Cha YN, Surh YJ. A protective role of nuclear factor-erythroid 2-related factor-2 (Nrf2) in inflammatory disorders. Mutat Res. 2010; 690(1-2): 12-23.

[101] Li W, Khor TO, Xu C, Shen G, Jeong WS, Yu S, et al. Activation of Nrf2-antioxidant signaling attenuates NFkappaBinflammatory response and elicits apoptosis. Biochem Pharmacol. 2008; 76(11): 1485-9.

[102] Abate A, Yang G, Dennery PA, Oberle S, Schroder H. Synergistic inhibition of cyclooxygenase-2 expression by vitamin E and aspirin. Free radical biology \& medicine. 2000; 29(11): 1135-42.

[103] Fu Y, Zheng S, Lin J, Ryerse J, Chen A. Curcumin protects the rat liver from CCl4-caused injury and fibrogenesis by attenuating oxidative stress and suppressing inflammation. Mol Pharmacol. 2008; 73(2): 399-409.

[104] Lee HS, Jung KK, Cho JY, Rhee MH, Hong S, Kwon M, et al. Neuroprotective effect of curcumin is mainly mediated by blockade of microglial cell activation. Pharmazie. 2007; 62(12): 937-42.

[105] Rahman S, Bhatia K, Khan AQ, Kaur M, Ahmad F, Rashid H, et al. Topically applied vitamin E prevents massive cutaneous inflammatory and oxidative stress responses induced by double application of 12-0tetradecanoylphorbol-13-acetate (TPA) in mice. Chem Biol Interact. 2008; 172(3): 195-205.

[106] Suzuki YJ, Aggarwal BB, Packer L. Alpha-lipoic acid is a potent inhibitor of NF-kappa B activation in human T cells. Biochem Biophys Res Commun. 1992; 189(3): 1709-15.

[107] Zhu J, Yong W, Wu X, Yu Y, Lv J, Liu C, et al. Anti-inflammatory effect of resveratrol on TNF-alpha-induced MCP-1 expression in adipocytes. Biochem Biophys Res Commun. 2008; 369(2): 471-7. 